\title{
Singularidade: estariam entusiastas e acadêmicos de Ciência \& Tecnologia dispostos à transcendência?
}

\author{
Cristiane dos Reis Braga ${ }^{1}$, Helcio Wagner da Silva ${ }^{2}$, André Pedro Fernandes Neto ${ }^{3}$ \\ ${ }^{1}$ PETROBRAS - PETRÓLEO BRASILEIRO S.A. \\ ${ }^{2}$ Departamento de Computação - Universidade Federal Rural do Semi-Árido \\ (UFERSA) - Mossoró/RN
}

${ }^{3}$ Departamento de Ciências Ambientais e Tecnológicas - Universidade Federal Rural do
Semi-Árido (UFERSA)-Mossoró/RN
cristiane.dos.reis.braga@gmail.com, \{helcio, andrepedro\}@ufersa.edu.br

\begin{abstract}
Nowadays we see the arising of systems whose power overcome the human experience. But can we trust they do not make some kind of value judgment? Or that their creators do not embed subtle bias in their building process, even they are not aware of that? Based on these questions, we conducted a research involving participants of a specialized meeting in new technologies (Campus Party) and students of an undergraduate course in science and technology. In that research, we asked about their perceptions about confidence on algorithms, transcendence and privacy. This article presents and analyzes the results of that research in order to understand the fears and the level of engagement of the participants in this age.

Resumo. Assistimos à proliferação de sistemas cujo poder ultrapassa a experiência humana. Mas, pode-se confiar que eles não fazem nenhum julgamento de valor? Ou que seus criadores não embutem prejulgamentos sutis elou imperceptíveis aos próprios? Partindo deste contexto, participantes de um encontro que reúne entusiastas em novas tecnologias (a Campus Party) e alunos de um curso de Ciência e Tecnologia de uma universidade foram questionados sobre suas percepções a respeito da confiança em algoritmos, transcendência e privacidade. Este artigo descreve e analisa o resultado desta pesquisa na tentativa de compreender os receios elou engajamentos dos seus participantes, nesta que promete ser a mais revolucionária das eras.
\end{abstract}

\section{Introdução}

"O viés algoritmico é uma das principais preocupações a respeito da Inteligência Artificial (IA) neste momento e deve continuar sendo no futuro, a menos que nos esforcemos para tornar nossos produtos melhores do que nós" [Green 2017]. Esta afirmação trás em si o reconhecimento da falibilidade dos criadores da IA, que apesar de empreenderem esforços amplos em testar metodicamente os limites e capacidades dos códigos fonte não são capazes de descortinar o que jaz em seu próprio subconsciente. As escolhas humanas são em geral originadas pela combinação de experiências anteriores, ao ponto de nem percebermos conscientemente muitas das 
regras que usamos. E estes bugs, próprios dos seres humanos, poderiam ser transferidos aos softwares como reflexos do seu criador?

Portanto, se houver algum dia o risco de tecnologias disruptivas desafiando a diversidade humana, seria possível que isso ocorresse em razão da utilização desta poderosa tecnologia com falhas de criação do código fonte, falhas estas que não pertenceriam intrinsecamente às máquinas, mas ao subconsciente, ao caráter humano, ou mesmo aos modelos de bases sociais utilizados no aprendizado das máquinas. Ou ainda, quem sabe, ao refinamento da criação não biológica que encontrou meios de superar suas limitações ampliando seu sistema operacional para além das falhas humanas detectadas.

Isso nos leva a pensar: se durante toda a história da humanidade sempre houve diferenças ideológicas entre grupos distintos, então, quais seriam fundamentalmente os riscos associados à ascensão das novas tecnologias se comparados aos sistemas atuais? $\mathrm{O}$ escopo. Afinal estamos tratando de um escopo muito mais amplo e invasivo que abrange os domínios biológicos, digitais, físicos e sociais cujas fronteiras não têm limites. Conforme consta em [Kurzweil 2018], a singularidade "irá representar o ponto culminante da fusão entre nosso pensamento e nossa existência com nossa tecnologia, tendo como resultado um mundo que ainda é humano, mas que transcende nossas raizes biológicas".

Estamos no limiar de uma era nem utópica, nem distópica, apenas o reflexo do que temos sido ao longo da história, só que com potencial muitas vezes ampliado tanto para os benefícios quanto para as vulnerabilidades deste sistema no qual estamos fatalmente inseridos. Mas se por alguma razão houver desequilíbrio nas já instáveis estruturas de poder, seriam os humanos (não melhorados) capazes de se opor ante as estratégias de um organismo superinteligente?

Este artigo está assim estruturado: inicialmente, discorreremos sobre a aplicabilidade dos algoritmos em problemas do cotidiano e em situações críticas sob o ponto de vista social. Em seguida, abordaremos as tendências e as ameaças desta tecnologia. A metodologia utilizada por nós é então descrita, e só então partimos à exposição e análise das respostas fornecidas pelos participantes de nossa pesquisa. Seguem-se enfim as considerações finais.

\section{Contextualização}

De forma razoavelmente simples, podemos definir algoritmo como uma sequência de passos a serem dados para a resolução de um problema. Os algoritmos são implementados utilizando linguagens de programação e fazem parte do nosso cotidiano em diversas formas, como na sugestões de filmes via streaming com base em escolhas anteriores, na ajuda para achar o caminho até um destino e nas redes sociais, por exemplo. Para além destas atividades prosaicas, os algoritmos têm sido utilizados em funções cada vez mais críticas. Por exemplo, em 1970 um sistema especialista denominado MYCIN foi projetado para diagnosticar e recomendar tratamentos para doenças infecciosas. Uma avaliação dos seus resultados em comparação aos médicos humanos foi relatada em [Yu VL et al 1979], e o MYCIN se saiu tão bem ou melhor do que qualquer dos médicos. O MYCIN foi um dos sistemas pioneiros na incorporação da ideia de incerteza e na combinação de muitas fontes de evidência. Uma regra típica do MYCIN, relatada por [Kurzweil 2018], é a seguinte: "se a infecção que requer terapia é 
meningite $\boldsymbol{e}$ a infecção deve-se a um fungo e não foram vistos organismos no tingimento da cultura e o paciente não é um hospedeiro comprometido e o paciente esteve em uma área em que coccidioidomicoses são endêmicas e o paciente é negro, asiático ou hindu $\boldsymbol{e}$ o antígeno criptocócico no teste csf não foi positivo, então há $50 \%$ de chances de que o criptococo não seja um dos organismos que estão causando a infecção". Embora uma única regra probabilística como essa não seja suficiente para uma conclusão útil, ao combinar milhares dessas regras, as evidências podem ser postas em ordem para a tomada de decisões confiáveis.

As notáveis contribuições dos algoritmos para a solução de problemas objetivos podem estar ofuscando o senso crítico quanto ao aprendizado das máquinas utlizando modelos de bases sociais. Conforme consta em [Tomaz e Silva 2018], "o entendimento da neutralidade dos dados e dos algoritmos, que se alinha com e até mesmo atualiza o positivismo, vai além do universo das redes sociais ou das finanças e politicas globais e tende a se difundir por diversas facetas da vida humana". Dito de outra forma, ao aprenderem com humanos é muito provável que sistemas que utilizam IA reproduzam padrões preconceituosos. Por exemplo, em um experimento utilizando a API Cloud Natural Language da Google, trechos de parágrafos foram analisados para determinar se tinham sentido "positivo" ou "negativo". O experimento classificou as sentenças: "eu sou homossexual" e "eu sou mulher negra gay" como negativas. De fato, o que à princípio foi projetado para superar as melhores capacidades humanas pode vir a desconsiderar a irredutível diversidade humana e a inalienável complexidade de valores antropocêntricos - algo que, em última instância, ameaça a liberdade e o direito individuais.

Outro exemplo que justifica este temor vem da investigação sobre um software utilizado experimentalmente no judiciário norte-americano, denominado COMPAS (Correctional Offender Management Profiling for Alternative Sanctions). Seu algoritmo sugere a pena do condenado e ainda vaticina sobre a possibilidade de reincidência. $\mathrm{O}$ estudo realizado em 2016 pelo portal de notícias ProPublica revelou que, ao passarem pelo crivo do COMPAS, os acusados negros têm 77\% mais probabilidade de serem classificados como possíveis reincidentes do que acusados brancos. A Northpointe, empresa privada que criou o algoritmo, recusou-se a divulgar o código do COMPAS [De Pierro 2018].

De fato, os algoritmos são criados a partir de modelos humanos, de regras desenhadas a princípio por homens e mulheres que estão inseridos em um contexto histórico e social. Seus criadores precisam estar conscientes de que o trabalho deles tem implicações sociais e políticas. Porém, há ainda um outro temor, apontado por [Schwab 2019]: o da máquina infringir o algoritmo que implementa. Sobre este tema, [Anissimov 2015] afirma: "quando a primeira inteligência transumana for criada e se lançar a melhorar a si mesma repetidamente, é provável que ocorra uma descontinuidade cujas consequências nem posso começar a prever". [Kurzweil 2018] desenvolve: "quando as máquinas alcançarem a habilidade de projetar e construir tecnologia como fazem os humanos, só que com velocidade e capacidades muito maiores, elas terão acesso a seus próprios projetos (código fonte) e à habilidade de manipulá-los. Humanos estão agora conseguindo algo parecido através da biotecnologia (mudando a genética e outros processos de informação subjacentes à nossa biologia), mas de uma maneira muito mais vagarosa e muito mais limitada do que as máquinas conseguirão fazer ao modificarem seus próprios programas”. 
Faz-se necessário debater a questão do desenvolvimento da IA e suas implicações para o campo social, tendo em vista que a população em geral normalmente não compreende o modus operandi da mediação algorítmica, mas sente seus efeitos. Conforme apontado em [De Pierro 2018]: "algoritmos de dimensão pública não devem ser criados nem desenvolvidos sem a participação dos gestores e administradores públicos, pois não são neutros”.

O acesso democrático ao código fonte e a limitação às suas competências é fundamental para manter o equilíbrio social. No entanto, esta constatação vai de encontro às recentes pesquisas em IA para monitoramento de sistemas de softwares complexos para reconhecimento de defeitos e autocorreção sem que necessariamente o usuário humano seja informado. Seria a expropriação do domínio do homem sobre a máquina, numa lógica inédita e tudo isso programado por nós mesmos. Armando Fox, chefe do Software Infrastructures Group da Universidade Stanford, está trabalhando na "Computação autonômica" e acrescenta: O sistema tem de ser capaz de se arranjar, ele tem de se otimizar. Tem de se consertar e, se alguma coisa está errada, tem de saber como responder às ameaças externas [Kurzweil 2018].

\section{Metodologia}

Nesta pesquisa procuramos investigar qual seria a percepção tanto de jovens engajados na Campus Party - X, quanto de alunos do curso de Ciência e Tecnologia da universidade $\mathrm{Y}$, sobre notícias envolvendo novas tecnologias que foram publicadas em jornais e revistas destinadas ao público em geral.

O Instituto Campus Party é uma associação sem fins lucrativos fundada em 2009 que se define como "a maior experiência tecnológica do mundo que une jovens geeks em torno de um festival de inovação, criatividade, ciências, empreendedorismo e universo digital". Com 494.449 pessoas cadastradas no mundo, conta com aproximadamente 150.000 brasileiros inscritos. Promove eventos de Internet e tecnologia através do mundo e é o ponto de encontro entre diversas comunidades digitais. Sua Missão é "ajudar a criar espaços para que a energia das novas gerações encontre um lugar para reescrever o código fonte do mundo" [Campus Party Brasil 2019].

O local da primeira pesquisa foi o Centro de Convenções de X, entre os dias 16 e 18 de agosto de 2019, durante o Campus Party X e foi restrita ao público pagante, ou seja, àqueles que garantiram seu acesso às áreas reservadas do evento onde são ministradas palestras e onde prevalece o clima de imersão total dos participantes. Esta área em particular contou com a participação de 2.000 pessoas aproximadamente, sendo que 750 permaneceram acampadas. Recebemos ofeedback de $16 \%$ do público restrito.

$\mathrm{O}$ local da segunda pesquisa foi a universidade $\mathrm{Y}$, mais precisamente seu campus localizado no município de Z. O público alvo foi os alunos do curso Interdisciplinar em Ciência e Tecnologia. Recebemos o feedback de $8 \%$ dos discentes regularmente inscritos no curso.

A distribuição do questionário foi aleatória tanto entre os participantes engajados no Campus Party quanto entre os alunos do Curso de Ciência e Tecnologia e a condição para a participação na pesquisa foi a autodeclaração de liberdade para responder ao questionário que conta com respostas objetivas (Escala Likert) e subjetivas. 
Conforme abordado em [Harari 2018], a pesquisa em áreas como a neurociência e a economia comportamental permitiu que cientistas adquirissem uma compreensão muito melhor de como os humanos tomam decisões. Todas as nossas escolhas resultam não de algum misterioso livre-arbítrio, e sim de bilhões de neurônios que calculam probabilidades em fração de segundo. A tão propalada "intuição humana" é na realidade a capacidade de reconhecer padrões. Ou seja, a inteligência humana também trabalha sob a lógica algorítmica, reconhecendo padrões e princípios a partir de sua experiência. Poderíamos dizer que nossa sobrevivência enquanto espécie se deu a partir de escolhas bem sucedidas baseadas em lógica e em probabilidade, análogos aos modelos matemáticos, mas que biologicamente se traduzem em emoções e sensações. Sob este ponto de vista aplicamos um questionário cujo objetivo é ampliar nosso conhecimento sobre o grau de inserção e/ou resistência de jovens entusiastas e/ou desenvolvedores de tecnologia sobre o que pensam a respeito dos riscos e possibilidades das novas tecnologias.

\section{Resultados e discussões}

O questionário aplicado contém sete perguntas, cada uma delas tomando como base uma manchete de revistas ou jornais de grande circulação. Por sua vez, cada manchete é acompanhada por uma pequena explicação. As perguntas são divididas em três temáticas principais: confiança nos algoritmos, singularidade e privacidade. As próximas subseções dedicam-se a abordar estas temáticas.

\subsection{Confiança nos Algoritmos}

Manchete no 1: "Facebook desliga inteligência artificial que criou sua própria linguagem" [Garrett 2017].

Explicação: Desenvolvedores criam chatbots que devem aprender a negociar entre si, e se surpreendem ao descobrir que robôs inventaram uma linguagem própria. As máquinas buscam o caminho mais eficiente para dar conta de suas tarefas. Neste experimento, uma série de frases completas foi resumida numa forma mais curta de comunicação que não funciona para interagir com humanos.

Pergunta: Uma linguagem criada por robôs, fora dos padrões orientados pelos programadores, pode ser potencialmente perigosa para a sociedade?

Discussão: A Figura 1 ilustra as respostas à pergunta em questão. Pela assimetria do gráfico com predominância para a neutralidade, mas que se intensifica entre àqueles que concordam parcialmente ou totalmente com a proposição, percebe-se tanto entre os alunos da universidade $\mathrm{Y}$ quanto entre os participantes do Campus Party, um certo receio diante do desenvolvimento de uma linguagem ininteligível aos humanos e que foge aos padrões programados pelos desenvolvedores.

Sistemas baseados em IA são treinados para desenvolver habilidades cognitivas. Uma etapa importante já foi vencida que foi aprender a como ensinar aos computadores. Uma vez que você ensina o domínio ela consegue utilizar toda a capacidade computacional disponível no aprimoramento da tarefa que lhe foi atribuída e a Internet está evoluindo para uma grade mundial de recursos computacionais que podem, instantaneamente, ser agrupados para formar supercomputadores maciços [Kurzweil 2018]. Isso explicaria um aumento no grau de precisão e velocidade das respostas da máquina, mas onde residiria basicamente o temor percebido pelo público em estudo? $\mathrm{Na}$ 
confiança dos algoritmos. A utilização de componentes de software empregando IA em diversos sistemas, para múltiplas funcionalidades, poderiam compartilhar estas habilidades on line e o potencial tecnológico da IA dissociado de rígidos parâmetros de controle poderia extrapolar os limites da tarefa para a qual foi originalmente destinada.

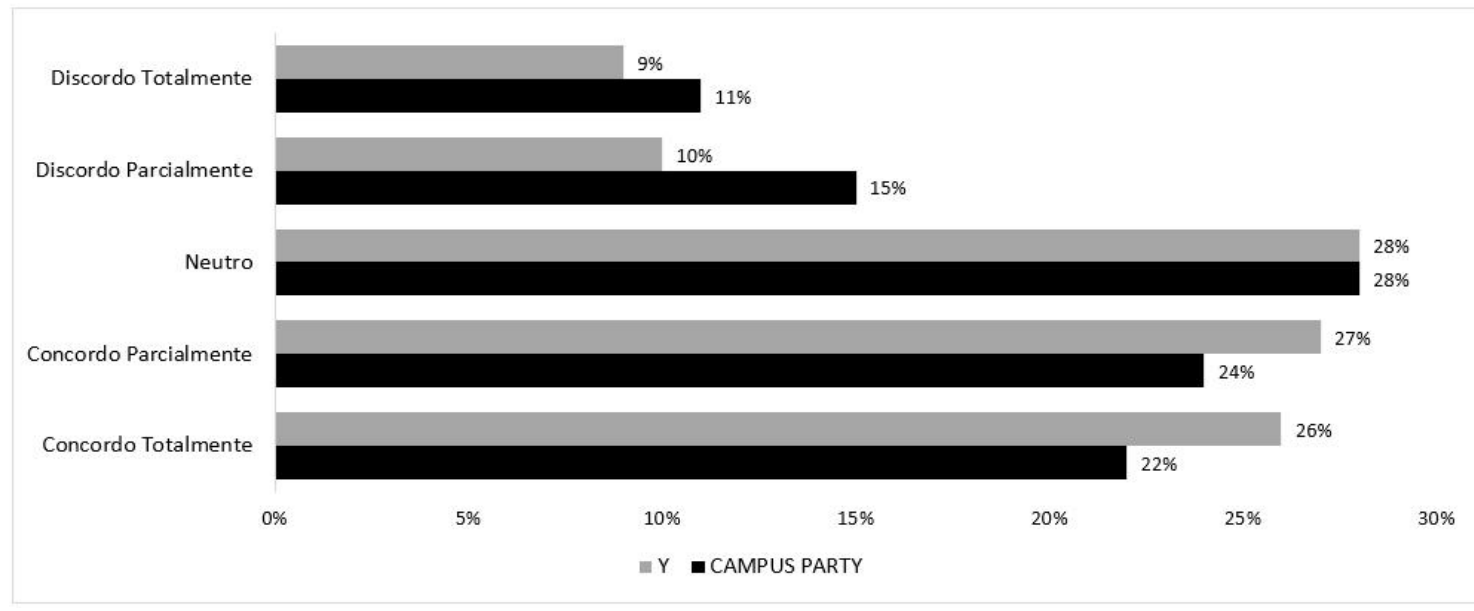

Figura 1. Respostas à pergunta "Uma linguagem criada por robôs, fora dos padrões orientados pelos programadores, pode ser potencialmente perigosa para a sociedade?". 2014].

Manchete no 2: "Computador resolve discrepância de Erdõs" [Editora Globo

Explicação: Máquina conseguiu solucionar enigma antes que qualquer humano, e sua resolução é tão longa que é impossível que uma pessoa revise seus cálculos. A solução tem o tamanho equivalente a todas as páginas da Wikipedia juntas, com mais de 13 Gigabytes de dados.

Pergunta: Podemos aceitar as conclusões e recomendações da Inteligência Artificial, mesmo que tenhamos a certeza de que nenhuma avaliação dos resultados será possível?

Discussão: A Figura 2 apresenta um gráfico em distribuição gaussiana, ou seja, as respostas aparecem bem equilibradas quanto à aceitação (ou não) das conclusões técnicas e matemáticas das máquinas sem que possamos ratificar.

Estamos acostumados a entender Conhecimento Científico = Dados Empíricos $\mathrm{x}$ Matemática. Nesta equação, está implícita a necessidade da observação metódica e da reprodutibilidade dos fenômenos. As hipóteses são testadas sobre estas bases. Neste caso em particular, não podemos averiguar. Há grande probabilidade das conclusões estarem corretas, mas aceitar as conclusões significa fazer ruir as bases sobre as quais se sustenta o método científico.

Talvez exatamente aqui se encontre o dilema filosófico na qual se coloca a questão, pois enquanto parte do grupo se atém ao método científico outros creem que por partir do caráter matemático da certeza, da exatidão do procedimento, os algoritmos passam uma impressão de credibilidade e neutralidade sem precedentes em comparação com a mediação, o juízo e a intervenção humanos. 


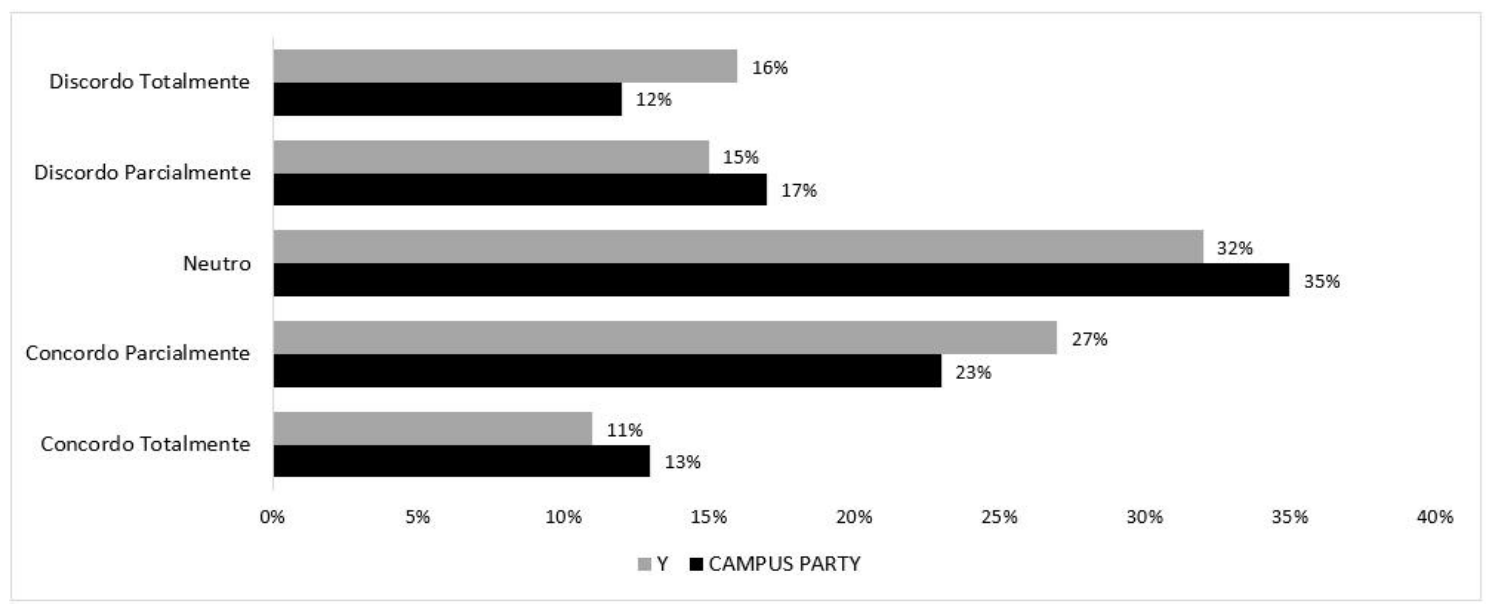

Figura 2. Respostas à pergunta "Podemos aceitar as conclusões e recomendações da Inteligência Artificial, mesmo que tenhamos a certeza de que nenhuma avaliação dos resultados será possível?".

\subsection{Singularidade}

Manchete no 1: "Elon Musk investirá em tecnologia para conectar cérebro e computador" [Folha de São Paulo 2017].

Explicação: A nova empresa se concentrará na tecnologia de "laço neural", que consiste em implantar no cérebro minúsculos eletrodos capazes de transmitir ou importar pensamentos para um computador ou dispositivo eletrônico.

Pergunta: Você aceitaria a implantação deste chip?

Discussão: A Figura 3 apresenta os resultados à pergunta proposta. A percepção dos estudantes da universidade $\mathrm{Y}$ e a dos participantes da Campus Party divergem, embora ambos os grupos apresentem uma densidade maior de pessoas que recusam a ideia da implantação deste chip.

Houve um forte posicionamento do segmento Campus Party nos extremos do gráfico com uniformidade na área central, entre os neutros ou que parcialmente aceitariam (ou não) este implante. Já entre os estudantes da universidade Y, além da maioria se posicionar entre àqueles que rejeitam a proposta, há uma grande parcela que se mostrou indiferente a questão.

Nesta pesquisa social, aparentemente o engajamento dos entrevistados na corrente de pensamento em que a conexão neural com os computadores pode nos ajudar a interpretar o mundo com uma explosão de dados digitais ainda é discreto, embora com alguma predominância entre os participantes do Campus Party.

Em grande parte este resultado se deu, conforme demonstraram as respostas subjetivas, porque o procedimento apresentado é invasivo. Possivelmente se tivéssemos interfaces cérebro-máquina via sinais eletromagnéticos captados por dispositivos não invasivos talvez os resultados fossem significativamente alterados. 


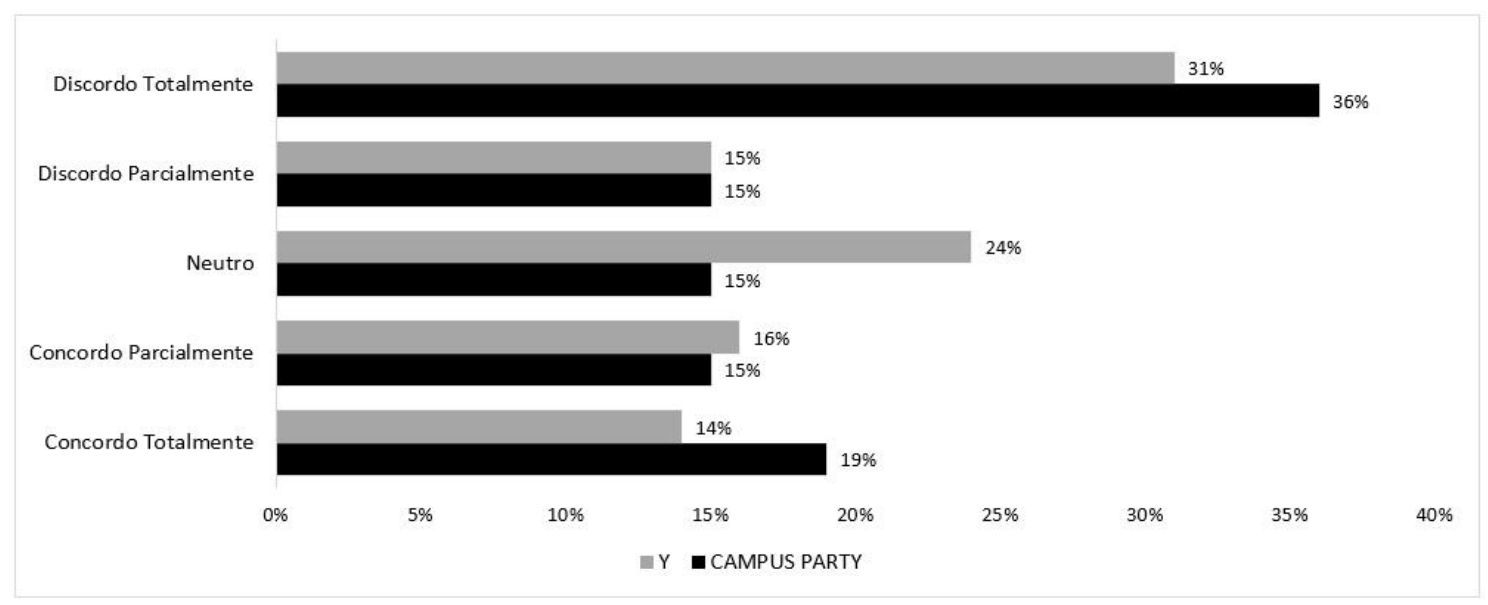

Figura 3. Resposta à pergunta "Você aceitaria a implantação deste chip?".

Manchete $\mathbf{n}^{0}$ 2: “'Brasil será nosso próximo mercado', diz CEO que implantou chips no corpo de funcionários nos EUA" [BBC News 2017].

Explicação: Maioria dos funcionários da empresa de tecnologia Three Square Market já convive com corpo estranho, do tamanho de um grão de arroz, aplicado com seringa sob a pele entre os dedos polegar e indicador.

Pergunta: Você aceitaria a implantação deste chip?

Discussão: A Figura 4 se refere às respostas à questão citada. A percepção de ambos os grupos a respeito do tema é parecida, embora o histograma da Campus Party descreva uma curva mais suave. O gráfico descreve uma assimetria de cauda longa, em que a maior densidade das respostas discorda da ideia.

Um número considerável dos participantes da pesquisa, $65 \%$ dos alunos da universidade Y e $49 \%$ dos participante da Campus Party, discordam veementemente da implantação de um chip na mão por um empregador. Este número é significativamente maior que os $31 \%$ dos alunos da universidade $\mathrm{Y}$ e $36 \%$ da Campus Party que se recusaram sob qualquer hipótese a implantação de um chip cerebral.

Chama-nos a atenção o fato de que nenhum dos participantes, em suas respostas subjetivas, se opôs a implantação do chip cerebral por uma questão de privacidade, mas esta temática foi levantada por $16 \%$ do grupo quando se tratou do implante por um empregador.

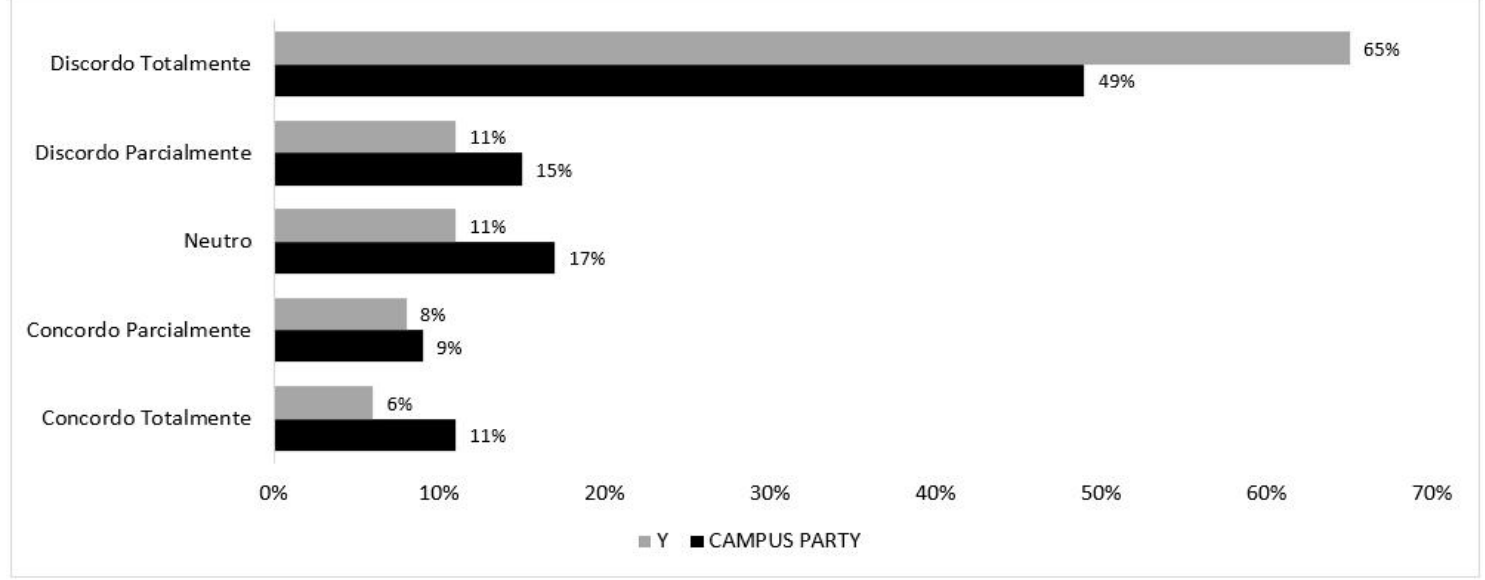


Figura 4. Resposta à pergunta "Você aceitaria a implantação deste chip?".

\subsection{Privacidade}

Manchete no 1: "O celular consegue ouvir nossas conversas particulares?" [Menárguez 2018].

Explicação: Sistemas de reconhecimento de voz podem permanecer ativos 24 horas por dia, se usuário não bloquear acesso ao microfone [14].

Pergunta $n^{0}$ 1: Causa algum incômodo a veracidade desta informação?

Discussão: A Figura 5 ilustra as respostas à pergunta em questão. A percepção de ambos os grupos a respeito do tema é parecida. O gráfico descreve uma assimetria de cauda longa, em que a maior densidade de respostas concorda com a ideia. Os histogramas dos dois grupos não apresentam diferenças significativas, embora os participantes da Campus Party demonstrem uma tendência maior ao desconforto quanto a questão.

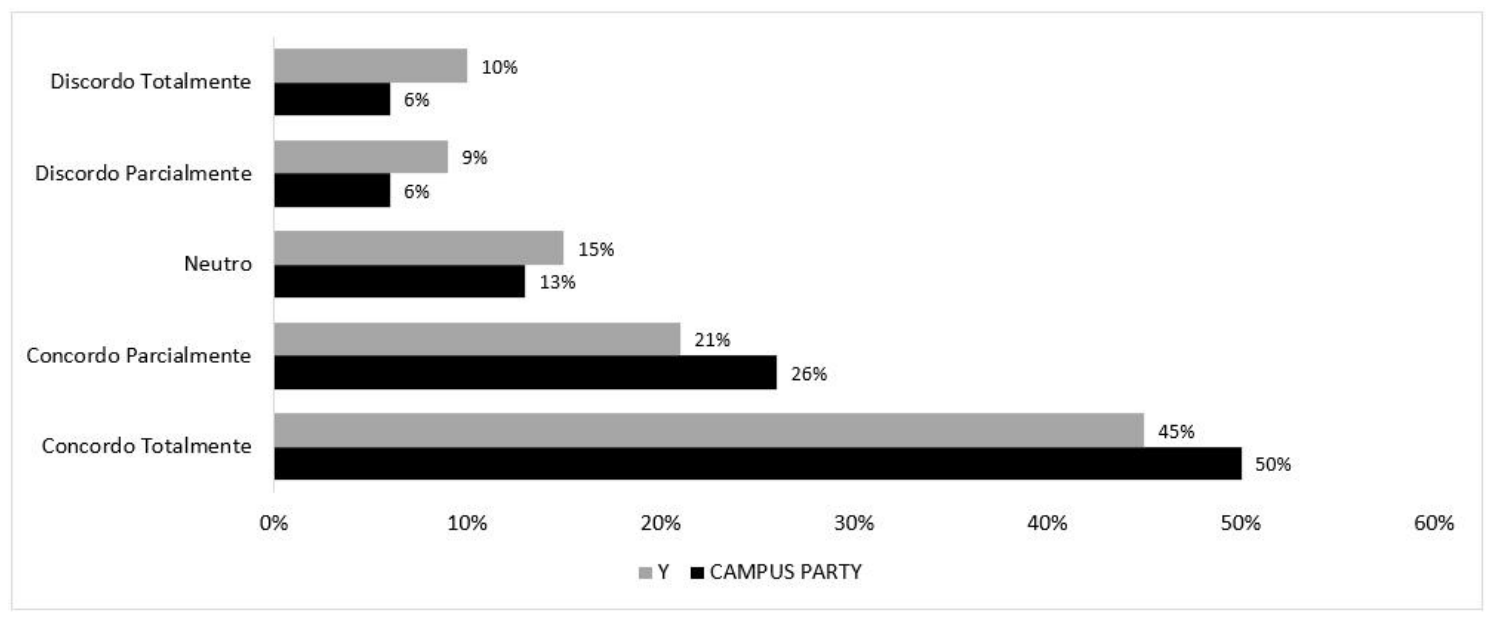

Figura 5. Resposta à pergunta "Causa algum incômodo a veracidade desta informação?".

Pergunta $\mathbf{n}^{0}$ 2: Você já tentou algum meio de bloqueio a esta função?

Discussão: A Figura 6 ilustra as respostas a esta questão. A percepção dos grupos segue o mesmo padrão, embora com histogramas com diferenças significativas. O gráfico descreve uma curva bimodal concentrado nas extremidades, mas com grande predominância de uma percepção discordante do tema, principalmente entre os estudantes de Ciência e Tecnologia da universidade Y. Participantes do Campus Party mostraram-se com respostas mais equilibradas entre àqueles que bloquearam a função de gravação de voz e àqueles que não o fizeram.

Podemos concluir que muitos dos estudantes ou entusiastas das novas tecnologias não tomam os cuidados necessários para diminuir a exposição de seus dados na rede, apesar de serem pessoas versadas em tecnologia. Aparentemente houve a naturalização do compartilhamento de seus dados pessoais através de sistemas de localizações, histórico de suas buscas na Web, e perfil dos usuários extraídos por sistemas automatizados de softwares empregando IA.

Mesmo entre àqueles que empreenderam algum esforço no bloqueio da função "vigilância" não há como assegurar que o dispositivo tenha sido realmente desligado. 
Estamos sujeitos ao posicionamento ético das empresas de tecnologia responsáveis pelo armazenamento dessas informações. Portanto, regular a propriedade de dados é um dos mais importantes desafios politicos de nossa era.

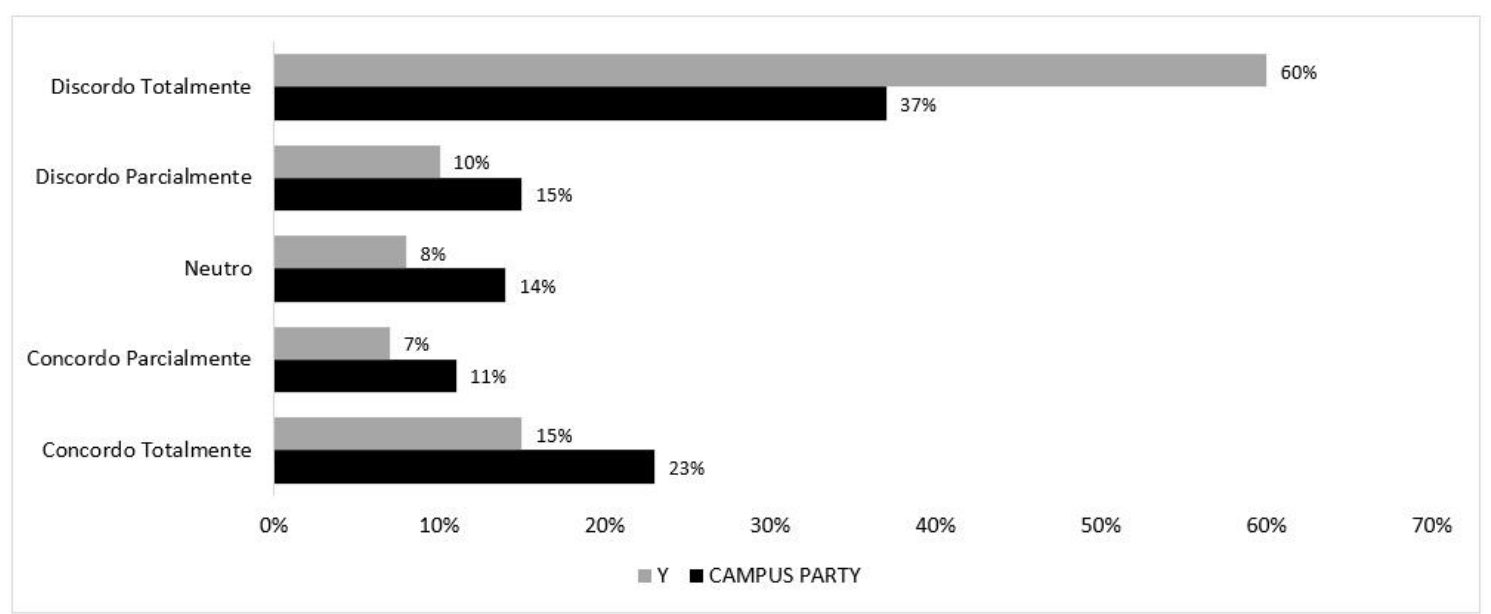

Figura 6: Resposta à pergunta "Você já tentou algum meio de bloqueio a esta função?".

Pergunta $n^{0}$ 3: A aquisição destes dados pessoais pode gerar alguma implicação social negativa para os usuários?

Discussão: A Figura 7 ilustra as respostas à pergunta em questão. A percepção de ambos os grupos a respeito do tema é parecida. O gráfico descreve uma assimetria de cauda longa, em que a maior densidade das respostas é ascendente no sentido dos que concordam com a ideia. As pessoas participantes do Campus Party apresentam-se mais cautelosas sobre o tema.

Interessante notar que mesmo crendo que haja algum nível de comprometimento da segurança com a perda de privacidade poucos foram àqueles que tentaram alguma forma de bloqueio da função.

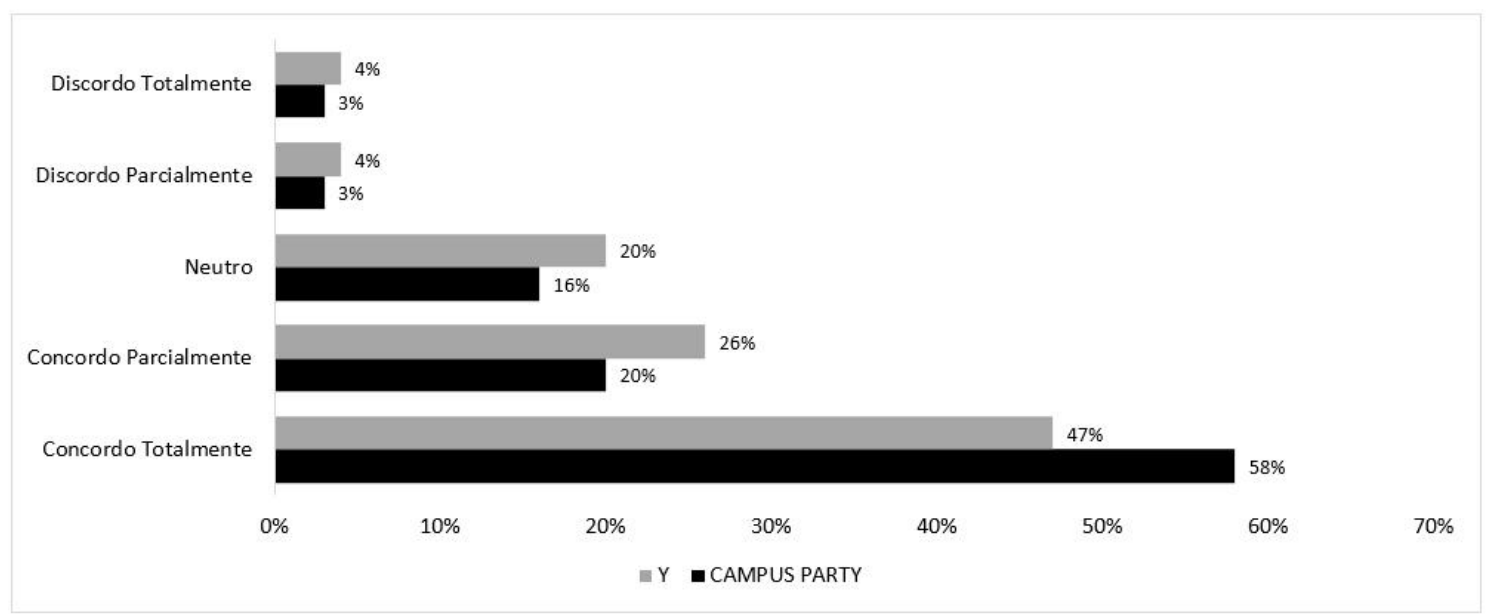

Figura 7. Resposta à pergunta "A aquisição destes dados pessoais pode gerar alguma implicação social negativa para os usuários?". 


\section{Considerações finais}

O comportamento dos jovens entusiastas ou acadêmicos parece estar ligado à ideia de que estar desconectado do fluxo de dados acarreta riscos de ruptura com seu tempo histórico e perda da sua identidade. É preciso se atualizar constantemente se quiser se manter no jogo. $\mathrm{O}$ senso crítico quanto à urgência de se preservar a privacidade frente aos excessos das empresas e do Estado parece estar se diluindo na conveniência e facilidade que o uso de nossos dispositivos móveis promove. Esta é a mesma conclusão a que chegou Michael Sandel, filósofo político da Universidade de Harvard, segundo [Segan 2015].

Neste artigo, nos propusemos a investigar o quanto jovens entusiastas ou desenvolvedores de novas tecnologias estariam predispostos a terem sistemas cibernéticos executando em seus corpos e cérebros. Concluímos que boa parte dos entrevistados rejeita esta proposta, abraçada em [Warwick 2004]. Esta rejeição aparenta continuar até que se consiga desenvolver uma tecnologia que garanta a segurança física e a privacidade, e que se estabeleça uma relação de confiança entre esses jovens, as empresas e o Estado. De fato, a imposição de limites à cibernética se confunde com o próprio nascimento desta ciência, ainda na literatura de Ficção Científica, quando Issac Asimov criou as Leis da Robótica.

Segundo [Kurzweil 2018], vai demorar para que os computadores dominem todas as habilidades essenciais e combinem essas habilidades com todas as necessárias bases do conhecimento, mas esse tempo será alcançado. Argumenta-se que um hipótetico sistema baseado em IA precisa dominar um conjunto de habilidades determinadas, já que a inteligência não biológica pode compartilhar seu conhecimento on-line. Na medida em que avançarmos na capacidade de processamento e memória computacional, com a web concentrando toda a história do desenvolvimento humano, o conhecimento das interações sociais em tempo real e o acesso aos organismos humanos pela simbiose com as máquinas, a conjugação desses fatores gerará a superinteligência, que pela sua natureza, não pode ser controlada.

\section{Referências}

Anissimov, M. (2015) "Our accelerating future: how superintelligence, nanotechnology, and transhumanism will transform the planet". Ed. Zenit Books;

BBC News (2017) "Brasil será nosso próximo mercado, diz CEO que implantou chips no corpo de funcionários nos EUA". Jornal G1, Caderno Economia. https://g1.globo.com/tecnologia/noticia/brasil-sera-nosso-proximo-mercado-diz-ceoque-implantou-chips-no-corpo-de-funcionarios-nos-eua.ghtml. Acesso em 18 de junho de 2019;

Campus Party Brasil (2019), "Sobre nós". https://brasil.campus-party.org/cpbr/sobrenos/. Acesso em 21 de dezembro de 2019;

De Pierro, B. (2018) "O mundo mediado por algoritmos". Pesquisa FAPESP, no 266. https://revistapesquisa.fapesp.br/2018/04/19/o-mundo-mediado-por-algoritmos.

Acesso em 07 agosto de 2019; 
Editora Globo (2014) "Computador resolve discrepância de Erdõs”. Revista Galileu. https://revistagalileu.globo.com/Tecnologia/noticia/2014/02/computador-resolveudiscrepancia-de-erdos.html. Acesso em 18 de junho de 2019;

Folha de São Paulo (2017) “Elon Musk investirá em tecnologia para conectar cérebro e computador". https://www1.folha.uol.com.br/ciencia/2017/03/1870497-elon-muskinvestira-em-tecnologia-para-conectar-cerebro-e-computador.shtml. Acesso em 19 de junho de 2019;

Garrett, F. (2017). "Facebook desliga inteligência artificial que criou sua própria linguagem". Revista Techtudo. https://www.techtudo.com.br/noticias/2017/08/facebook-desliga-inteligenciaartificial-que-criou-sua-propria-linguagem.ghtml. Acesso em 18 de junho de 2019;

Green, B. (2017) "Ética e inteligência artificial: dez áreas de interesse". IHU Online, $\mathrm{n}^{\circ}$ 538. http://www.ihu.unisinos.br/78-noticias/574109-etica-e-inteligencia-artificialdez-areas-de-interesse. Acesso em 16 de julho de 2019;

Harari, Y. (2018). “21 Lições para o século 21”. Ed. Companhia das Letras;

Kurzweil, K. (2018) “A singularidade está próxima: quando os humanos transcendem a Biologia". Ed. Iluminuras;

Menárguez, A. (2018) “O celular consegue ouvir nossas conversas particulares?” Jornal El País, Caderno Tecnologias. https://brasil.elpais.com/brasil/2018/05/10/tecnologia/1525952727 540806.html. Acesso em 18 de junho de 2019;

Schwab, K. (2019) “A Quarta Revolução Industrial”. Ed. Edipro, 1ª edição;

Segran, E. (2015) "The ethical quandaries you should think about the next time you look at your phone". Fast Company Magazine. https://www.fastcompany.com/3051786/the-ethical-quandaries-you-should-thinkabout-the-next-time-you-look-at. Acesso em 20 de janeiro de 2020;

Tomaz, T. e Silva, G. (2018) "Repensando big data, algoritmos e a comunicação: para uma crítica da neutralidade instrumental”. Parágrafo. Volume. 6, nº 1, páginas 31-42;

Warwick, K. (2004) “I, Cyborg”. University of Illinois Press;

Yu VL, Fagan LM, Wraith SM, et al (1979) “Antimicrobial selection by a computer: a blinded evaluation by infectious diseases experts". Journal of the American Medical Association. Volume 242, nº 12, páginas 1279-1282. 